\title{
Association Between Obstetric Violence and Symptoms Suggestive of Postpartum Depression
}

Janini Cristina Paiz ( $\square$ janinicpaiz@gmail.com )

Universidade Federal do Rio Grande do Sul (UFRGS)

Stela Maris Jezus Castro

Universidade Federal do Rio Grande do Sul (UFRGS)

Elsa Regina Justo Giugliani

Universidade Federal do Rio Grande do Sul (UFRGS)

\section{Sarah Maria Santos Ahne}

Universidade Federal do Rio Grande do Sul (UFRGS)

Camila Bonalume Dall'Aqua

Universidade Federal do Rio Grande do Sul (UFRGS)

Camila Giugliani

Universidade Federal do Rio Grande do Sul (UFRGS)

\section{Research Article}

Keywords: Violence, postpartum depression, childbirth, obstetric care

Posted Date: November 15th, 2021

DOI: https://doi.org/10.21203/rs.3.rs-1034466/v1

License: (c) (i) This work is licensed under a Creative Commons Attribution 4.0 International License.

Read Full License 


\section{Abstract}

Background: Postpartum depression is a common condition in the pregnancy and postpartum cycle. The development of this condition is multifactorial and can be influenced by previous traumas. This study sought to verify whether there is an association between having been exposed to obstetric violence and presenting symptoms suggestive of postpartum depression.

Methods: This is a cross-sectional study, with the inclusion of 287 women without complications in childbirth, randomly selected from two maternity hospitals of Porto Alegre, southern Brazil, in 2016. Four weeks after delivery, the postpartum women answered a face-to-face interview about socioeconomic aspects, obstetric history, health history, and childbirth experience (practices and interventions applied) and completed the Edinburgh Postnatal Depression Scale (EPDS). From the perception of women regarding the practices performed in the context of childbirth care, a composite variable was created, using item response theory, to measure the level of obstetric violence. The items that made up this variable were: absence of a companion during delivery, feeling insecure and not welcome, lack of privacy, lack of skin-to-skin contact after delivery, not having understood the information shared with them, and not having felt comfortable to ask questions and make decisions about their care. To define symptoms suggestive of postpartum depression, reflecting on increased probability of this condition, the EPDS score was set at $\geq 8$. Poisson Regression with robust variance estimation was used for modeling.

Results: Women who experienced obstetric violence had a higher prevalence of symptoms suggestive of postpartum depression (PR 1.55 95\% Cl 1.07-2.25), as well as those with a history of mental health problems (PR 2.41 95\% Cl 1.15-5.05), while higher socioeconomic status ( $A$ and $B$ ) had an inverse association (PR 0.38 95\% $\mathrm{Cl}$ 0.19-0.78).

Conclusions: Symptoms suggestive of postpartum depression seems to be more prevalent in women who have suffered obstetric violence, of low socioeconomic status, and with a history of mental health problems. Thus, qualifying care for women during pregnancy, childbirth and postpartum and reducing social inequalities are challenges to be faced in order to reduce the occurrence of postpartum depression.

\section{Background}

Postpartum depression (PPD) is a psychiatric disorder, characterized by a predominance of depressed mood, associated with sleep disorders, feelings of worthlessness and guilt, excessive worry, difficulty concentrating, weight changes, among other symptoms, which in extreme cases can lead women to suicidal thoughts [1]. These symptoms can appear during the gestational period, soon after birth, or up to one year after delivery. PPD causes personal suffering and social dysfunction, in addition to interfering in the mother's relationship with the child [2-4]).

According to the World Health Organization [5], about $10 \%$ of pregnant women and $13 \%$ of postpartum women worldwide suffer from some mental disorder, depression being the main one. In developing countries, this prevalence is $15.6 \%$ and $19.8 \%$ for pregnant and postpartum women, respectively. The 
different forms and methods used for diagnosis, and the characteristics of the populations studied, interfere in the estimation of the prevalence of PPD [5].

In clinical practice, screening is ideally done by asking two questions that investigate whether, in the last month, the woman has been troubled feeling depressed or hopeless; or has had little interest or pleasure in doing daily tasks [4]. If the answer is affirmative for either of the two questions, screening for PPD is recommended by applying the Edinburgh Postnatal Depression Scale - EPDS [6]. This scale is able to identify symptoms that may be associated with depressive conditions. However, the diagnosis of PPD depends on further medical evaluation to define the diagnosis [7].

PPD has a multifactorial etiology. Among the agents involved in its causality are the rapid drops in hormone levels, previous negative life events, individual susceptibilities to the development of depressive conditions, low levels of social support, marital instability, domestic violence, as well as work overload, changes in routine and sleep patterns, and the feeling of disability involved in the postpartum period $[8,9]$.

Recent researches investigate the association between mistreatment, disrespect and abuse in childbirth care - situations defined as obstetric violence - with the development of symptoms and presentation of PPD $[10,11]$. Obstetric violence is a public health problem, experienced worldwide by many women, and can be defined as a violation of human rights in a period of women's vulnerability [10,12]. Categorized as a gender-based violence, it can be expressed by verbal disrespect, physical or psychological abuse, discrimination, neglect, lack of privacy, limitation in access to information, and application of unconsented procedures [13-15].

The magnitude of obstetric violence varies widely, according to the different surveys conducted, with prevalence ranging from $6-98 \%[13,16,17]$. This variation arises from the heterogeneity in the measurement of the phenomenon and recognition (or non-recognition) of the different practices performed by health professionals as abusive, disrespectful and without an evidence base for their benefits $[16,18]$.

In the international context, studies show the existence of an association between traumatic experiences in childbirth and higher incidence of post-traumatic stress, anxiety and depression in the early (one week after birth) and late postpartum (04, 06, 12 and 24 weeks postpartum) $[19,20]$. In this same direction, there are the results of research conducted in Brazil, which demonstrated an association between having suffered disrespect, abuse or violence during childbirth and having PPD [10,21]. When analyzing its subcategories, significant association was found between having suffered verbal violence and developing moderate and severe PPD and having suffered physical violence and developing severe PPD.

The harms of PPD are not restricted to the women. Studies show that children of women with this condition are at higher risk of hospitalizations (RR 1.93; $\mathrm{Cl} 95 \%$ 1.02-3.64) and mortality in the first year of life (RR 1.44; Cl 95\% 1.10 - 1.89) [22]. In the long term, these children are twice as likely to develop behavioral disorders, anxiety, depression, concentration deficits, and lower performance in school subjects such as mathematics [23,24]. 
Therefore, early identification of PPD symptoms and screening of women at higher risk for this disorder is essential for diagnosis and management. Considering that obstetric violence seems to be a risk factor for developing PPD, it becomes relevant to further explore this association, making it possible to intervene in order to promote the women's quality of life, including a positive motherhood experience. Thus, the aim of this study is to verify the existence of an association between obstetric violence and symptoms suggestive of PPD in a sample of women four weeks postpartum.

\section{Methods}

\section{Study design, population and power calculation}

A cross-sectional study, with inclusion of postpartum women who gave birth in two large maternity hospitals (one public and one private) of Porto Alegre, Rio Grande do Sul (RS), was conducted. The women were randomly selected, by drawing, in services responsible for approximately $25 \%$ of the 30,268 deliveries that occurred in the state capital city in 2016.

All women living in Porto Alegre who gave birth to full-term newborns in the two participating maternity hospitals were eligible. Women or newborns with unfavorable outcomes at delivery (death or admission to intensive care) or who presented formal contraindication for breastfeeding were excluded from the study, to avoid biases in the measurement for perception of obstetric violence, postpartum depression, and other outcomes of interest in the research that originated this study $[25,26]$. Women living in areas at risk for home visits were also excluded to preserve the safety of the research team.

For the current study, the power calculation was performed prospectively, considering the sample of 287 women, to meet the objective of identifying the association between obstetric violence and symptoms suggestive of postpartum depression. The power calculated to identify an odds ratio equal to 2.5 , in a model adjusted for age, skin color, education, socioeconomic status, living with a partner, parity, mental health problems, alcohol use, and pregnancy planning, considering a significance level of $5 \%$, was equal to $85.3 \%$. The power calculation was performed in the SAS Studio software.

\section{Data collection}

Data collection occurred between January and August 2016. Every day, all women who had given birth in the previous 24 hours and met the inclusion criteria received a number that was used for the draw. Each day, two women from the public maternity hospital and one from the private hospital were included in the study until the intended sample was reached. This proportion aimed to ensure a reasonable representation in relation to the use of public and private services, described in the literature as being around $70 \%$ and $30 \%$, respectively, at national level $[27,28]$.

In the period from 31 to 37 days after delivery, an interview was conducted at the home or, rarely, in another place at the woman's preference, to apply a structured questionnaire, which was specifically designed for this study, based on the previous experience of the researchers and the guiding documents 
of childbirth care in Brazil $[29,30]$. Women who were not found for the interview, after at least three attempts of telephone contact and one in person, were considered a loss.

The interviews were conducted after a pilot study that indicated the need for minor semantic adjustments to the questionnaire. The field team was composed of 12 interviewers trained for the job. Weekly meetings were held with the field team, seeking greater uniformity in data collection.

\section{Statistical Aspects}

The outcome variable of this study was symptoms suggestive of PPD. To identify these symptoms, the EPDS instrument was used, a self-administered questionnaire with 10 items, which considers the seven days preceding the interview. Each item has four possible answers, with a score associated to symptom severity. This score ranges from 0 to 3 ( 0 : no change and; 3 : significant mood change). The aspects evaluated by means of the EPDS are: ability to laugh, to find things funny, thoughts about the future, feelings (guilt, anxiety, worry, panic, overload and unhappiness), the desire to cry and to do harm to oneself [7]. The instrument has scores ranging from zero to 30 , according to validation carried out in Brazil, values close to zero indicate low or no risk of PPD, while values close to or greater than 10 indicate susceptibility to PPD [31].

Considering the severity of symptoms for women and children, and the outcome of interest in this study (symptoms suggestive of PPD), and not of possible depression, which is usually based on scores between 11 and 13 [17,31], we chose to use a score $\geq 8$ points of the EPDS. This cut-off point increases the sensitivity of the instrument and allows symptomatic women, albeit with a lower score, to be identified. Previous research has already suggested that a score $\geq 8$ points performs better on diagnostic tests for depressive symptoms [32]

The choice of this cut-off point is also justified by the validation of the instrument (with score $\geq 8$ ) in the general population, in a scenario with sociodemographic, cultural, and climatic characteristics very similar to those of the present study. This study showed that the $\geq 8$ cut-off point had a sensitivity of $80 \%$ and $84.4 \%$ and a specificity of $87 \%$ and $81.3 \%$, for the general population and women, respectively [33].

The exposure of interest was obstetric violence, measured by means of a binary variable that categorized postpartum women for having or not suffered obstetric violence, constructed from the latent trait Level of Obstetric Violence (Nível de Violência Obstétrica - NVO). This measure, which was defined with mean zero and standard deviation 1, was based on an instrument composed of nine items calibrated by the twoparameter logistic model of Item Response Theory (IRT) [34] The items that composed the NVO were: not having had a companion during the prepartum, labor, and postpartum period, not having understood the information provided by professionals, not having had privacy during labor, not having felt comfortable to ask questions and participate in decisions about their care, not having felt welcomed and safe at the delivery environment, and not having had immediate skin-to-skin contact with the baby. The cut-off point of the NVO scale defining whether or not she had experienced obstetric violence was 0.5 standard 
deviation above the mean. The full presentation of the development of this measure has been described in a paper that is currently submitted for publication.

Other variables were used for adjustment in this study to reduce confounding biases: age, skin color, education, socioeconomic status, living with a partner, mental health problems, alcohol use, last planned pregnancy, and parity.

As these data are from a cross-sectional study and the objective was to estimate the magnitude of the association (prevalence ratio) between the predictor obstetric violence and the outcome symptoms suggestive of PPD, the Poisson regression model with robust variance estimation was used for the analyses. The software used for the analyses were SAS Studio and SPSS 21.

\section{Results}

Of the women drawn, 379 were eligible to participate in the study. Of these, 287 were interviewed. There were $25(6.6 \%)$ refusals, and $67(17.7 \%)$ were lost due to failure in contacting to schedule the interviews. The women not interviewed differed in terms of education and skin color, showing less education $(p<0.01)$ and a higher prevalence of white skin color compared to those interviewed $(p=0.032)$. Table 1 presents the characteristics of the women interviewed regarding sociodemographic factors, obstetric and health history, and childbirth care. 
Table 1

Sociodemographic, obstetric history, and childbirth care characteristics according to the frequency of symptoms of PPD.

\section{Sample $n(\%) \quad$ Symptoms suggestive of PPD (EPDS $\geq 8$ ) - $n$}

(\%)

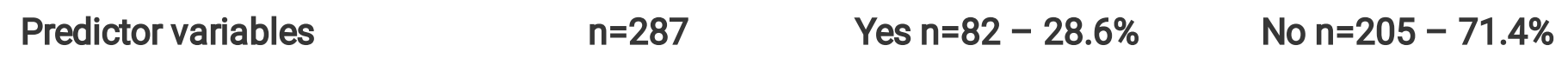

\section{Sociodemographic}

Age (year)

$\leq 19$ years

$23(8.0)$

$7(30.4)$

$16(69.6)$

20-34 years

199 (69.3)

$58(29.1)$

141 (70.9)

$\geq 35$ years

$65(22.6)$

$17(26.2)$

48 (73.8)

\section{Color of skin}

White

$216(75.3)$

$66(30.6)$

$150(69.4)$

Black or brown

$71(24.7)$

16(22.5)

$55(77.5)$

Socioeconomic level $(n=285)$

$\begin{array}{llll}\text { A - B } & 163(57.2) & 38(23.3) & 125(76.7) \\ \text { C - D - E } & 122(42.8) & 44(36.1) & 78(63.9)\end{array}$

\section{Education}

College

124 (43.2)

$34(27.4)$

$90(72.6)$

Elementary and high school

$163(56.8)$

$48(29.4)$

$115(70.6)$

\section{Lives with a partner}

Yes

$248(86.4)$

$70(28.2)$

$178(71.8)$

No

39 (13.6)

$12(30.8)$

$27(69.2)$

\section{Health status and Reproductive history}

\section{Mental health problem}

Current or past

No

\section{Previous births}

One or two
$38(13.2)$

$249(86.8)$

$65(26.1)$

$21(55.3)$

$184(73.9)$

17 (44.7)

$72(30.0)$

$168(70.0)$

$\mathrm{N}$ other than 287 due to missing data were inserted immediately after the variable name. EPDS:

Edinburgh Postnatal Depression Scale 
Sample $n$ (\%) Symptoms suggestive of PPD (EPDS $\geq 8$ ) - $n$

(\%)

$\begin{array}{llll}\text { Three or more } & 47(16.4) & 10(21.3) & 37(78.7)\end{array}$

\section{Last pregnancy planned}

$\begin{array}{llll}\text { Yes } & 154(53.7) & 41(26.6) & 113(73.4) \\ \text { No } & 133(46.3) & 41(30.8) & 92(69.2)\end{array}$

\section{Childbirth care}

Hospital status

Public

$188(65.5) \quad 57(30.3)$

$131(69.7)$

Private

$99(34.5)$

$25(25.3)$

$74(74.7)$

Had a companion

\begin{tabular}{llll} 
Prepartum & $275(95.8)$ & $79(28.7)$ & $196(71.3)$ \\
\hline Delivery & $283(98.6)$ & $80(28.3)$ & $203(71.7)$ \\
\hline Postpartum & $275(95.8)$ & $78(28.4)$ & $197(71.6)$
\end{tabular}

Felt comfortable asking questions $(n=284)$

$\begin{array}{llll}\text { Yes } & 241(84.9) & 69(28.6) & 172(71.4) \\ \text { No } & 43(15.1) & 12(27.9) & 31(72.1)\end{array}$

Understood information received

\begin{tabular}{llll} 
Yes & $251(87.5)$ & $67(26.7)$ & $184(73.3)$ \\
\hline No & $36(12.5)$ & $15(41.7)$ & $21(58.3)$ \\
\hline Went into labor & & & $141(68.8)$ \\
\hline Yes & $205(71.4)$ & $64(31.2)$ & $64(78.0)$ \\
\hline No & $82(28.6)$ & $18(22.0)$ &
\end{tabular}

Had skin-to-skin contact with the newborn $(n=281)$

$\begin{array}{llll}\text { Yes } & 191(68.0) & 61(31.9) & 130(68.1) \\ \text { No } & 90(32.0) & 18(20.0) & 72(80.0)\end{array}$

Felt welcomed in the birth environment $(n=281)$

$\mathrm{N}$ other than 287 due to missing data were inserted immediately after the variable name. EPDS: Edinburgh Postnatal Depression Scale 


\begin{tabular}{|c|c|c|c|}
\hline & Sample n (\%) & \multicolumn{2}{|c|}{$\begin{array}{l}\text { Symptoms suggestive of PPD (EPDS } \geq 8)-n \\
(\%)\end{array}$} \\
\hline Yes & $220(78.3)$ & $58(26.4)$ & $162(73.6)$ \\
\hline No & $61(21.7)$ & $23(37.7)$ & $38(62.3)$ \\
\hline \multicolumn{4}{|c|}{ Felt safe in the birth environment $(n=282)$} \\
\hline Yes & $209(74.1)$ & $54(25.8)$ & $155(74.2)$ \\
\hline No & $73(25.9)$ & $26(35.6)$ & $47(64.4)$ \\
\hline \multicolumn{4}{|c|}{ Had privacy during birth $(n=280)$} \\
\hline Yes & $235(83.9)$ & $70(29.8)$ & $165(70.2)$ \\
\hline No & $45(16.1)$ & $11(24.4)$ & $34(75.6)$ \\
\hline
\end{tabular}

The sample was composed predominantly of women aged between 20 and 34 years, white, with high income and education, and who resided with their partner. Slightly more than half of the women had planned their last pregnancy. Regarding protagonism and care in childbirth, $15.1 \%$ of the women did not feel comfortable asking questions and participating in decisions, and $32 \%$ did not have skin-to-skin contact with their babies. The prevalence of symptoms suggestive of PPD, considering the cut-off point $\geq 8$ was $28.6 \%$. Table 2 shows the analysis of association of sociodemographic, health, and obstetric factors with the highest frequency of symptoms suggestive of PPD. These factors were subsequently included in the multivariable model of association between the exposure variable (obstetric violence) and the outcome. 
Table 2

Evaluation of factors associated with symptoms suggestive of PPD in postpartum women.

\begin{tabular}{|c|c|c|c|}
\hline Factors & $\begin{array}{l}\text { PRC } \\
\text { (Cl 95\%) }\end{array}$ & $\begin{array}{l}\text { PRA } \\
\text { (CI 95\%) }\end{array}$ & P-val \\
\hline \multicolumn{4}{|l|}{ Age (years) } \\
\hline Mean + SD & $0.99(0.96-1.01)$ & $1.00(0.97-1.07)$ & 0.857 \\
\hline \multicolumn{4}{|l|}{ Color of skin } \\
\hline White & $1.34(0.83-2.16)$ & $1.54(0.96-2.47)$ & 0.071 \\
\hline Black or brown & 1.00 & 1.00 & \\
\hline \multicolumn{4}{|l|}{ Socioeconomic level } \\
\hline$A-B$ & $0.65(0.45-0.93)$ & $0.53(0.33-0.83)$ & 0.006 \\
\hline$C-D-E$ & 1.00 & 1.00 & \\
\hline \multicolumn{4}{|l|}{ Education } \\
\hline College (complete or incomplete) & $0.92(0.63-1.33)$ & $1.11(0.70-1.79)$ & 0.648 \\
\hline Elementary and high school & 1.00 & 1.00 & \\
\hline \multicolumn{4}{|l|}{ Lives with partner } \\
\hline Yes & $0.90(0.54-1.49)$ & $0.91(0.53-1.58)$ & 0.748 \\
\hline No & 1.00 & 1.00 & \\
\hline
\end{tabular}

\section{Previous births}

One or two

$0.70(0.39-1.26)$

$0.64(0.32-1.27)$

0.203

Three or more

1.00

1.00

\section{Planned pregnancy}

Yes

$1.16(0,80-1,67)$

$1.04(0.71-1.51)$

0.841

No

1.00

1.00

\section{Mental health condition}

Yes

$1.75(1.17-2.63)$

$1.69(1.16-2.47)$

0.006

No

1.00

Alcohol Use

* Poisson with robust variance estimation, p-value relative to the adjusted analysis. PRC: crude prevalence ratio, PRA: adjusted prevalence ratio. 


\begin{tabular}{|llll|}
\hline Factors & $\begin{array}{l}\text { PRC } \\
(\text { Cl 95\%) }\end{array}$ & $\begin{array}{l}\text { PRA } \\
(\mathrm{Cl} \text { 95\%) }\end{array}$ & P-value* \\
\hline Yes & $0.91(0.63-1.31)$ & $0.84(0.57-1.25)$ & 0.398 \\
\hline No & 1.00 & 1.00 & \\
\hline $\begin{array}{l}\text { * Poisson with robust variance estimation, p-value relative to the adjusted analysis. PRC: crude } \\
\text { prevalence ratio, PRA: adjusted prevalence ratio. }\end{array}$ & & \\
\hline
\end{tabular}

Women with a history of mental health problems had a higher prevalence of symptoms suggestive of PPD (PR 2.41; 95\% Cl 1.15-5.05). On the other hand, women with higher income had lower prevalence of these symptoms (PR 0.38; 95\% Cl 0.19-0.78).

Table 3 shows the association between obstetric violence and symptoms suggestive of PPD, with adjustment for confounding factors.

Table 3

Association between obstetric violence and symptoms suggestive of PPD.

\begin{tabular}{|c|c|c|}
\hline Model & PR (CI 95\%) & P-value* \\
\hline Model 1 & $1.581(1.090-2.293)$ & 0.016 \\
\hline Model 2 & $1.584(1.092-2.298)$ & 0.015 \\
\hline Model 3 & $1.594(1.094-2.323)$ & 0.015 \\
\hline Model 4 & $1.576(1.085-2.289)$ & 0.017 \\
\hline Model 5 & $1.494(1.041-2.145)$ & 0.029 \\
\hline Model 6 & $1.548(1.067-2.247)$ & 0.021 \\
\hline \multicolumn{3}{|c|}{$\begin{array}{l}\text { PR: prevalence ratio. * Poisson with robust variance estimation, } p \text {-value relative to the adjusted } \\
\text { analysis. }\end{array}$} \\
\hline \multicolumn{3}{|c|}{ Model 1 = Obstetric violence } \\
\hline \multicolumn{3}{|c|}{ Model 2 = Obstetric violence + age } \\
\hline \multicolumn{3}{|c|}{ Model 3 = Model $2+$ skin color + education + lives with partner } \\
\hline \multicolumn{3}{|c|}{ Model 4 = Model $3+$ socioeconomic level } \\
\hline \multicolumn{3}{|c|}{$\begin{array}{l}\text { Model } 5=\text { Model } 4+\text { mental health condition }+ \text { planned pregnancy }+ \text { previous births } \\
\text { Model } 6=\text { Model } 5+\text { alcohol use }\end{array}$} \\
\hline
\end{tabular}

The association between obstetric violence and symptoms suggestive of PPD was significant both in the crude analysis (PR 1.581; 95\% Cl 1.09-2.29) and in the adjusted models. In Model 6, with a greater 
number of adjustment variables, a PR of $1.55(95 \% \mathrm{Cl} 1.07-2.27)$ was found, with little variation in the summary measure and confidence interval after different adjustment models (Table 3 ).

\section{Discussion}

Maternal depression is one of the most common mental health problems during pregnancy and childbirth, with important effects on women, children, and their families. Negative experiences related to childbirth have been associated with the occurrence of psychiatric problems, such as depression and post-traumatic stress $[19,20]$.

Our study identified $28.6 \%$ of women having symptoms suggestive of PPD using the cutoff point of $\geq 8$ on the EPDS). We identified a significant association between obstetric violence and higher frequency of symptoms suggestive of PPD. Even after adjustment (for socioeconomic variables, mental health history, parity and pregnancy planning), women who suffered obstetric violence had a $50 \%$ higher prevalence of symptoms suggestive of PPD. This association possibly stems from the vulnerability related to childbirth, and the frustrations regarding the woman's expectations about the moment, the divergence between what is expected and the experience of abuse; humiliation and mistreatment trigger the trauma, which with the postpartum hormonal changes are exacerbated and favor the development of PPD.

Other studies investigating this association correlate the development of depressive symptoms with women's feelings of lack of control, not being provided with information at birth, experiencing physical pain, humiliation and abandonment, not being cared for properly and undergoing procedures without consent, as well as being frustrated with their expectations at birth and concerned about their child's health [35-37].

It is important to note that the method of measuring obstetric violence adopted for this study differs from other surveys, because there is no standardized way to measure the latent variable, an issue also documented by other authors [21]. Added to this, the use of a lower cut-off point in the EPDS $(\geq 8)$ for defining symptoms suggestive of PPD, seeking greater sensitivity, limits the comparison of this study with other surveys.

The association between having suffered violence in childbirth and developing PPD was observed in other Brazilian settings $[17,21,38]$. Research conducted in the southernmost region [17] showed that having suffered verbal violence increases the chance of developing moderate PPD by more than $50 \%$ $(\mathrm{OR}=1.58 ; 95 \% \mathrm{Cl} 1.06-2.33)$ and severe PPD by almost $70 \%(\mathrm{OR}=1.69 ; 95 \% \mathrm{Cl} 1.06-2.70)$, while having suffered physical violence more than doubles the chance of developing severe PPD (OR=2.28;95\% $\mathrm{Cl}$ 1.26-4.12). Another study conducted in Brazil identified a prevalence of postpartum depression of more than $50 \%$ in women who experienced physical, verbal, or negligent violence at childbirth [38].

In addition to obstetric violence, the present study identified low socioeconomic status and personal history of mental health problems (self-reported by the women) as factors associated with symptoms suggestive of PPD. These aspects have also been cited in other studies investigating factors associated 
with PPD or likely PPD conditions $[10,11]$. The authors suggest that women with a history of mental health problems have specific personal characteristics that may influence their perception of the care they receive [10,11]. Brown skin color, alcohol abuse, unplanned pregnancy, multiparity (3 or more) have been associated with likely cases of PPD in other investigations [10,11]. Education and marital status were significant in a study assessing postpartum emotional disorders [39], but were not significant in our study.

The course of PPD is variable [40], and may have complete remission, chronicity or relapses in subsequent pregnancies - a fact that negatively impacts the quality of life of women and the mother-baby binomial relationship, interfering in the cognitive, emotional and social development of the child [24]. These aspects should be taken into account by professionals who care for women in the pregnancypostpartum period, in order to reduce the trivialization/normalization of this condition.

This study uses a latent variable, called level of obstetric violence, constructed through a set of items, using IRT in modeling. The method, besides being statistically robust, evaluates each item of the measurement instrument according to its severity and discrimination capacity, allowing each one to have a different weight (importance) in estimating the level of violence. By using the composite variable - NVO (Level of Obstetric Violence) - it is possible to measure the impacts of the absence of a companion during labor, delivery and postpartum, of the women not having felt the childbirth environment welcoming, safe and private, of not having had skin-to-skin contact with their babies immediately after childbirth, and of not having understood information and had autonomy during childbirth.

Another potentiality of the present study refers to the methodological rigor in its conduction, with continuous quality control and face-to-face interviews four weeks after delivery in the homes of postpartum women, aspects that increase the methodological quality, once they reduce potential biases related to the intense sensations, exhaustion and lack of time to process the facts that occurred in the immediate postpartum period and the relativization and forgetfulness related to the passing of several months after the event.

As weaknesses of the study, we can point out the high number of losses, with respective reduction of the sample effectively investigated, which may have hidden the association of other exposure variables with the outcome. The use of a lower cut-off point $(\geq 8)$, less frequently used in research, limits the comparison of the findings of this study with those of other investigations and increases the proportion of false positives (1-specificity). However, in choosing this cut-off point, the highest sensitivity was valued, in search of a group of women at higher risk of developing PPD, since it is a screening and not a diagnostic tool.

\section{Conclusions}

Women who experienced violence in childbirth had a $55 \%$ higher prevalence of symptoms suggestive of PPD. The personal history of mental health problems more than doubled this prevalence, while the higher socioeconomic status reduced the prevalence by more than $60 \%$. Therefore, efforts to qualify childbirth 
care and minimize the occurrence of obstetric violence, still very present in the reality of maternity hospitals worldwide, are necessary to reduce the occurrence of postpartum depression and thus prevent the various negative outcomes resulting from this condition.

\section{Abbreviations}

Cl: Confidence Interval

EPDS: Edinburgh Postnatal Depression Scale

IRT: Item Response Theory

NVO: Level of Obstetric Violence

$\mathrm{N}$ : Number

O: Odd Ratio

PPD: Postpartum Depression

RP: Prevalence Ratio

PRA: Adjusted Prevalence Ratio

PRC: Crude Prevalence Ratio

RR: Relative Risk

RS: Rio Grande do Sul

SPSS: Statistical Package for the Social Sciences

UFRGS: Universidade Federal do Rio Grande do Sul

\section{Declarations}

\section{Ethics approval and consent to participate}

This study complies with the standards governing research with human subjects (Resolution 466/2012) and was approved by the research ethics committees (REC) of the institutions involved (Hospital de Clínicas de Porto Alegre - CAAE 49938015.3.0000.5327 and Hospital Moinhos de Vento 46775115.0.3002.5330). All women who agreed to participate in the study signed an informed consent form (ICF).

Consent for publication 
Not applicable.

\section{Availability of data and materials}

The datasets used and/or analyzed during the current study available from the corresponding author on reasonable request. All data generated or analyzed during this study are included in this published article.

\section{Competing interests}

The authors declare that they have no competing interests.

\section{Funding}

National Council for Scientific and Technological Development - CNPq.

\section{Authors' contributions}

JCP was involved in design of the study, collection, entering and interpreting of data, drafting and revision. SMJC was involved in interpretation of data, drafting and revision. ERJG was involved in design of the work, drafting and revision. SMSA was involved in interpretation of data, drafting and revision. CBDA was involved in interpretation of data and revision. CG was involved in design of the study, collection, entering and interpreting of data, drafting and revision. All authors have read and approved the manuscript.

\section{Acknowledgements}

The authors would like to thank Universidade Federal do Rio Grande do Sul, and the group of researchers who were part of the project, in all its phases. The contribution of each one was vital to the study.

\section{References}

1. Howard LM, Flach C, Mehay A, Sharp D, Tylee A. The prevalence of suicidal ideation identified by the Edinburgh Postnatal Depression Scale in postpartum women in primary care: findings from the RESPOND trial. BMC Pregnancy Childbirth. 2011;11:57. doi: 10.1186/1471-2393-11-57

2. American Psychiatric Association. Manual diagnóstico de transtornos mentais: DSM-5. American Psychiatric Association. Vol. 5. Porto Alegre: Artmed; 2014. 948 p.

3. Gaynes B, Gavin NI, Meltzer-Brody S, Lohr KN, Swinson T, Gartlehner G, et al. Perinatal Depression: prevalence, screening accuracy, and screening outcomes. Evid Rep Technol Assess. 2005;119:1-8. doi: 10.1037/e439372005-001

4. Stewart DE, Vigod S. Postpartum depression. New Engl J Med. 2016;375:2177-86. doi: 10.1056/NEJMcp 1607649

5. World Health Organization. Maternal and child mental health. 2016. https://www.who.int/teams/mental-health-and-substance-use/maternal-mental-health. Accessed 01 
oct 2021.

6. Myers ER, Aubuchon-Endsley N, Bastian LA, Gierisch JM, Kemper AR, Swamy GK, et al. Efficacy and safety of screening for postpartum depression. Agency for Healthcare Research and Quality (US); 2013

7. Cox JL, Holden JM, Sagovsky R. Detection of postnatal depression: development of the 10-item Edinburgh Postnatal Depression Scale. Br J Psychiatry. 1987;150:782-6. doi: 10.1192/bjp.150.6.782

8. Bloch M, Schmidt PJ, Danaceau M, Murphy J, Nieman L, Rubinow DR. Effects of gonadal steroids in women with a history of postpartum depression. Am J Psychiatry. 2000;157:924-30. doi: 10.1176/appi.ajp.157.6.924

9. Norhayati MN, Hazlina NH, Asrenee AR, Emilin WM. Magnitude and risk factors for postpartum symptoms: a literature review. J Affect Disord. 2015;175:34-52. doi: 10.1016/j.jad.2014.12.041.

10. Silveira MF, Mesenburg MA, Bertoldi AD, Mola CL, Bassani DG, Domingues MR, et al. The association between disrespect and abuse of women during childbirth and postpartum depression: findings from the 2015 Pelotas birth cohort study. J Affect Disord. 2019;256:441-7. doi:

10.1016/j.jad.2019.06.016.

11. Theme Filha MM, Ayers S, Gama SGN, Leal MDC. Factors associated with postpartum depressive symptomatology in Brazil: The Birth in Brazil National Research Study, 2011/2012. J Affect Disord. 2016;194:159-67. doi:10.1016/j.jad.2016.01.020

12. Diniz SG, Salgado HO, Andrezzo HFA, Carvalho PGC, Carvalho PCA, Aguiar CA, et al. Abuse and disrespect in childbirth care as a public health issue in brazil: origins, definitions, impacts on maternal health, and proposals for its prevention. J Hum Growth Dev. 2015;25(3):377-84. doi: 10.7322/jhgd.106080

13. Bohren MA, Vogel JP, Hunter EC, Lutsiv O, Makh SK, Souza JP, et al. The mistreatment of women during childbirth in health facilities globally: A mixed-methods systematic review. PLoS Med. 2015;12:1-32. doi: 10.1371/journal.pmed.1001847

14. Savage V, Castro A. Measuring mistreatment of women during childbirth: a review of terminology and methodological approaches. Reprod Health. 2017;14:138. doi: 10.1186/s12978-017-0403-5

15. Betron ML, McClair TL, Currie S, Banerjee J. Expanding the agenda for addressing mistreatment in maternity care: a mapping review and gender analysis. Reprod Health. 2018;15:143. doi: $10.1186 /$ s12978-018-0584-6

16. D’Orsi E, Brüggemann OM, Diniz CSG, Aguiar JM, Gusman CR, Torres JA, et al. Desigualdades sociais e satisfação das mulheres com o atendimento ao parto no Brasil: estudo nacional de base hospitalar. Cad Saúde Pública. 2014;30:S154-68. doi: 10.1590/0102-311X00087813

17. Mesenburg MA, Victora CG, Jacob Serruya S, Ponce DLR, Damaso AH, Domingues MR, et al. Disrespect and abuse of women during the process of childbirth in the 2015 Pelotas birth cohort. Reprod Health. 2018;15:54. doi: 10.1186/s12978-018-0495-6

18. Sando D, Abuya T, Asefa A, Banks KP, Freedman LP, Kujawski S, et al. Methods used in prevalence studies of disrespect and abuse during facility based childbirth: lessons learned. Reprod Health. 
2017;14:127. doi: 10.1186/s12978-017-0389-z

19. Schepper S, Vercauteren T, Tersago J, Jacquemyn Y, Raes F, Franck E. Post-Traumatic Stress Disorder after childbirth and the influence of maternity team care during labour and birth: a cohort study. Midwifery. 2016;32:87-92. doi: 10.1016/j.midw.2015.08.010

20. Reed R, Sharman R, Inglis C. Women's descriptions of childbirth trauma relating to care provider actions and interactions. BMC Pregnancy Childbirth. 2017;17:21. doi: 10.1186/s12884-016-1197-0

21. Leite TH, Pereira APE, Leal MC, Silva AAM. Disrespect and abuse towards women during childbirth and postpartum depression: findings from Birth in Brazil Study. J Affect Disord. 2020;273:391-401. doi: 10.1016/j.jad.2020.04.052

22. Jacques N. Prenatal and postnatal maternal depression and infant hospitalization and mortality in the first year of life: a systematic review and meta-analysis. J Affect Disord. 2019;243:201-8. doi: 10.1016/j.jad.2018.09.055

23. Netsi E, Pearson RM, Murray L, Cooper P, Craske MG, Stein A. Association of persistent and severe postnatal depression with child outcomes. JAMA Psychiatry. 2018;75:247-53. doi:10.1001/jamapsychiatry.2017.4363

24. Stein A, Pearson RM, Goodman SH, Rapa E, Rahman A, McCallum M, et al. Effects of perinatal mental disorders on the fetus and child. Lancet. 2014;384:1800-19. doi: 10.1016/S01406736(14)61277-0

25. Martins ACM, Giugliani ERJ, Nunes LN, Bizon AMBL, Senna AFK, Paiz JC, et al. Factors associated with a positive childbirth experience in Brazilian women: A cross-sectional study. Women and Birth. 2021;34:e337-45. doi: 10.1016/j.wombi.2020.06.003

26. Senna AFK, Giugliani C, Avilla J, Bizon AMBL, Martins ACM, Giugliani ERJ. Maternal satisfaction with breastfeeding in the first month postpartum and associated factors. Int Breastfeed J. 2020;15:72. doi: 10.1186/s13006-020-00312-w

27. Paim J, Travassos C, Almeida C, Bahia L, Macinko J. The Brazilian health system: history, advances, and challenges. Lancet. 2011;377:1778-97. doi: 10.1016/S0140-6736(11)60054-8

28. Viacava F, Oliveira RAD, Carvalho CC, Laguardia J, Bellido JG. SUS: supply, access to and use of health services over the last 30 years. Ciência e Saúde Coletiva. 2018;23:1751-62. doi: 10.1590/1413-81232018236.06022018

29. Brasil. Ministério da Saúde. Portaria no 1459, de 24 de junho de 2011: Rede Cegonha. 2011. https://bvsms.saude.gov.br/bvs/saudelegis/gm/2011/prt1459_24_06_2011.html. Accessed 20 oct 2021.

30. Brasil. Ministério da Saúde. Política nacional de atenção integral à saúde da mulher: princípios e diretrizes. Brasília: Ministério da Saúde. 2004. https://conselho.saude.gov.br/ultimas_noticias/2007/politica_mulher.pdf. Accessed 10 oct 2021.

31. Santos IS, Matijasevich A, Tavares BF, Barros AJD, Botelho IP, Lapolli C, et al. Validation of the Edinburgh Postnatal Depression Scale (EPDS) in a sample of mothers from the 2004 Pelotas Birth Cohort Study. Cad Saúde Pública. 2007;23:2577-88. doi: 10.1590/S0102-311X2007001100005 
32. Vivilaki VG, Dafermos V, Kogevinas M, Bitsios P, Lionis C. The Edinburgh Postnatal Depression Scale: translation and validation for a greek sample. BMC Public Health. 2009;9:329. doi: 10.1186/14712458-9-329

33. Matijasevich A, Munhoz TN, Tavares BF, Barbosa APPN, Silva DM, Abitante MS, et al. Validation of the Edinburgh Postnatal Depression Scale (EPDS) for screening of major depressive episode among adults from the general population. BMC Psychiatry. 2014;14:284. doi: 10.1186/s12888-014-0284-x

34. Andrade DF, Tavares HR, Valle RC. Teoria de Resposta ao Item: Conceitos e Aplicações. São Paulo: SINAPE; 2000. https://docs.ufpr.br/ aanjos/CE095/LivroTRI_DALTON.pdf. Accessed 30 sep 2021.

35. Schwab W, Marth C, Bergant AM. Post-traumatic Stress Disorder Post Partum: The Impact of Birth on the Prevalence of Post-traumatic Stress Disorder (PTSD) in Multiparous Women. Geburtshilfe Frauenheilkd. 2012;72:56-63. doi: 10.1055/s-0031-1280408.

36. Olde E, Hart O, Kleber R, Son M. Posttraumatic stress following childbirth: a review. Clin Psychol Rev 2006;26:1-16. doi: 10.1016/j.cpr.2005.07.002

37. Menage J. Post-traumatic stress disorder in women who have undergone obstetric and/or gynaecological procedures: a consecutive series of 30 cases of PTSD. J Reprod Infant Psychol 1993;11:221-8. doi: 10.1080/02646839308403222

38. Souza KJ, Rattner D, Gubert MB. Institutional violence and quality of service in obstetrics are associated with postpartum depression. Rev Saúde Pública. 2017;51:69. doi: 10.1590/s15188787.2017051006549

39. Iwanowicz-Palus G, Marcewicz A, Bień A. Analysis of determinants of postpartum emotional disorders. BMC Pregnancy Childbirth. 2021;21:517. doi: 10.1186/s12884-021-03983-3

40. Goodman JH. Postpartum depression beyond the early postpartum period. J Obstet Gynecol Neonatal Nurs. 2004;33:410-20. doi: 10.1177/0884217504266915 